\title{
Advanced SEM and TEM Techniques Applied in Mg-Based Hydrogen Storage Research
}

\author{
Jianding Li, ${ }^{1}$ Jincheng $\mathrm{Xu},{ }^{1}$ Bo Li, ${ }^{1}$ Liqing He $\mathbb{D},{ }^{2}$ Huaijun Lin $\mathbb{D},{ }^{3}$ Hai-Wen $\mathrm{Li}\left(\mathbb{D},{ }^{4}\right.$ \\ and Huaiyu Shao iD ${ }^{1}$ \\ ${ }^{1}$ Institute of Applied Physics and Materials Engineering (IAPME), University of Macau, Macau \\ ${ }^{2}$ Department of Materials Science and Engineering, Southern University of Science and Technology, Shenzhen 518055, China \\ ${ }^{3}$ Institute of Advanced Wear \& Corrosion Resistance and Functional Materials, Jinan University, Guangzhou 510632, China \\ ${ }^{4}$ Kyushu University Platform of Inter/Transdisciplinary Energy Research (Q-PIT), Kyushu University, Fukuoka 819-0395, Japan
}

Correspondence should be addressed to Liqing He; helq@sustc.edu.cn, Huaijun Lin; hjlin@jnu.edu.cn,

Hai-Wen Li; li.haiwen.305@m.kyushu-u.ac.jp, and Huaiyu Shao; hshao@umac.mo

Received 14 February 2018; Revised 12 May 2018; Accepted 16 May 2018; Published 17 July 2018

Academic Editor: Renato Buzio

Copyright (c) 2018 Jianding Li et al. This is an open access article distributed under the Creative Commons Attribution License, which permits unrestricted use, distribution, and reproduction in any medium, provided the original work is properly cited.

\begin{abstract}
Mg-based materials are regarded as one of the most promising candidates for hydrogen storage. In order to clarify the relationship between the structures and properties as well as to understand the reaction and formation mechanisms, it is beneficial to obtain useful information about the size, morphology, and microstructure of the studied materials. Herein, the use of scanning electron microscopy (SEM) and transmission electron microscopy (TEM) techniques for the representation of Mg-based hydrogen storage materials is described. The basic principles of SEM and TEM are presented and the characterizations of the size, morphology observation, phase and composition determination, and formation and reaction mechanisms clarification of $\mathrm{Mg}$ based hydrogen storage materials are discussed. The applications of advanced SEM and TEM play significant roles in the research and development of the next-generation hydrogen storage materials.
\end{abstract}

\section{Introduction}

Mg-based materials are thought to be very promising solid state hydrogen storage systems for mobile or stationary applications due to its low price, abundant resources, and high theoretical hydrogenation capacity [1-10]. However, the challenges of poor kinetics and improper thermodynamics seriously hindered their commercial applications. The situation of the little practical use of Mg-based hydrogen storage materials is mainly attributed to the extremely slow hydrogenation/dehydrogenation reaction, which occurs only at high temperatures (above $523 \mathrm{~K}$ ). In practice, an activation process of absorption/desorption also requires a high temperature of about $623 \mathrm{~K}$ and a hydrogen pressure of $70 \mathrm{~atm}$ without any additives [11]. It is reported that there are several reasons which may limit the reaction kinetics. The first one is that the magnesium oxide forms easily on the surface of $\mathrm{Mg}$ when the $\mathrm{Mg}$ particles are exposed to air. Moreover, the formed $\mathrm{MgO}$ layer on the surface of $\mathrm{Mg}$ would greatly prevent the contact of $\mathrm{Mg}$ and hydrogen molecules and hamper hydrogen penetration into the Mg-based materials to form a metal hydride. Another one is that the dissociation rate of hydrogen molecules on the metal surface is slow. Numerous efforts are required to improve the kinetics and to tailor the thermodynamics in Mg-based materials. To overcome these drawbacks, different nanoprocessing techniques are adopted to synthesize $\mathrm{Mg}$-based nanomaterials for hydrogen storage development. These techniques include ball milling, hydrogen plasma metal reaction (HPMR), catalyzed solution chemical synthesis, and nanoconfinement $[8$, 12-27]. Particularly, nanoprocessing for the synthesis of nanosized Mg-based materials has gained more and more interest because of the need to increase the surface contact between $\mathrm{Mg}$ and hydrogen and to reduce the diffusion distance for hydrogen in particles and grains [28-30]. Moreover, it is beneficial to represent the microstructures of $\mathrm{Mg}$ based hydrogen storage materials when researchers want to figure out the relationship between the structure and 
hydrogen storage performance. Lots of work have been reported on the study of the nanoscale structural characterization of a Mg-based hydrogen storage material by TEM and SEM techniques [31-41]. In some cases, in order to give direct evidence of the operating mechanisms, in situ scanning techniques can be used to directly understand the hydrogen reaction mechanism of $\mathrm{MgH}_{2}$ [42-46]. Here, the use of conventional electron microscopies as well as in situ techniques to observe the microstructure information in Mg-based materials and to understand the formation and reaction mechanisms during hydrogen storage processes is described. The main materials discussed in this work include the following:

(a) $\mathrm{Mg}$ and other alloy metal nanoparticles $(\mathrm{Ni}, \mathrm{Cu}, \mathrm{Co}$, $\mathrm{Fe}$, and $\mathrm{Al}$ ) synthesized by a hydrogen plasma metal reaction method (size measurements, morphology observation, and correlation study of properties and microstructure)

(b) $\mathrm{Mg}_{50} \mathrm{Co}_{50}$ alloy with a body-centered cubic (bcc) structure synthesized by ball milling for $100 \mathrm{~h}$ (size measurements and phase and composition determination)

(c) Mg thin-film sample deposited on a glass substrate by a sputtering method (size measurements)

(d) Commercial 325 mesh Mg from Alfa Aesar (morphology observation)

(e) $\mathrm{Mg}_{50} \mathrm{Co}_{50}$ samples ball milled for various durations (determination of the phase and composition and understanding the formation mechanism)

(f) $\mathrm{TiH}_{2}$ catalyzed a $\mathrm{MgH}_{2}$ nanocrystallite sample by a chemical solution synthesis method (phase and composition determination)

(g) $\mathrm{MgH}_{2}$ and $\mathrm{Mg}_{2} \mathrm{NiH}_{4}$ samples from the hydrogenation of $\mathrm{Mg}$ and $\mathrm{Mg}_{2} \mathrm{Ni}$ (in situ observation of hydrogen reaction mechanism)

\section{Application of SEM and TEM Techniques for Mg-Based Hydrogen Storage Research}

2.1. Size Measurements (Particle Size, Crystallite Size, Etc.). With the emerging of more and more nanotechnologies in the development of Mg-based hydrogen storage materials, it is important to obtain the size information in nanometer and micrometer scales, so that we may understand more about the size effect on hydrogen storage properties in these materials. There have been numerous analytic techniques for size measurements, such as electron microscopy, dynamic light scattering, X-ray diffraction and scattering, field flow fractionation, centrifugal liquid sedimentation, and atomic force microscopy. The TEM technique may provide a twodimensional picture of sample particles, which can be used for the size distribution evaluation in certain area ranges [47].

Figure 1 shows the TEM images of $\mathrm{Mg}, \mathrm{Ni}, \mathrm{Cu}, \mathrm{Co}, \mathrm{Fe}$, and $\mathrm{Al}$ nanoparticle samples obtained by a hydrogen plasma metal reaction method. All of these metal nanoparticles after HPMR synthesis show a granular structure. The particle sizes of these nanoparticle samples for various metals are quite different. $\mathrm{Mg}$ particles have a much larger size than the others. The average size of $\mathrm{Mg}$ particles is around $300-500 \mathrm{~nm}$, while the ones for $\mathrm{Ni}, \mathrm{Cu}, \mathrm{Co}, \mathrm{Fe}$, and $\mathrm{Al}$ are around $30-50 \mathrm{~nm}$. The difference is due to the much faster vaporization rate and higher synthesis rate of $\mathrm{Mg}$ than the other metals during the HPMR synthesis process. The evaporation rate depends much on the vaporized metals and it is strongly related to the melting points, boiling points, and saturation vapor pressures of these metals, which influence the size of the synthesized metal nanoparticles [48]. In Figure 1, we can see that the size and distribution of the particles may be easily obtained from TEM observation.

Figure 2 presents the SEM image and dark-field TEM image of the $\mathrm{Mg}_{50} \mathrm{Co}_{50}$ alloy with a bcc structure. This alloy with a metastable feature and unique microstructure was reported to be able to absorb hydrogen at $-15^{\circ} \mathrm{C}$, which is the lowest temperature reported so far for $\mathrm{Mg}$-based materials to absorb hydrogen $[8,49]$. The microstructure information of this sample can be obtained by SEM and TEM observations. From Figure 2(a), we can see that the $\mathrm{Mg}_{50} \mathrm{Co}_{50}$ alloy after ball milling has a homogenous particle size of around 1-2 $\mu \mathrm{m}$. From the dark-field TEM in Figure 2(b), we may find some crystallites inside a large particle of the $\mathrm{Mg}_{50} \mathrm{Co}_{50}$ alloy with a size of just a few nm, which is in agreement with the crystallite size calculated by the broadening of X-ray diffraction peaks [50-52]. The very fine particle size of 1-2 $\mu \mathrm{m}$, the crystallite size of a few $\mathrm{nm}$, and the bcc nonclose structure are thought to be the main factors of good kinetics at low temperature. In Figures 2(a) and 2(b), we can see that SEM focuses on the surface of the sample, while TEM may see more inside the particle or beyond the surfaces, which makes it possible to measure particle size by SEM observation on the surface and obtain crystallite size inside the particles via transmitted electrons illuminated in the image.

In Figure 3, we use the SEM technique to obtain the thickness size of the thin film. This size is needed for the calculation of thermal diffusivity and thermal conductivity of thin-film samples. From Figure 3, the boundary of the $\mathrm{Mg}$ film with the glass substrate is clear and it can be clearly observed that the layer thickness is about $84 \mathrm{~nm}$. With this value, the thermal diffusivity and thermal conductivity of the $\mathrm{Pd}$-capped $\mathrm{Mg}$ thin film are calculated to be $4.62 * 10^{-5} \mathrm{~m}^{2} / \mathrm{s}$ and $82.0 \mathrm{~W} / \mathrm{m} / \mathrm{K}$, respectively. When we compare the thermal conductivity and hydrogen absorption kinetics with several other Mg-based materials (325 mesh Mg, Mg single crystal (0001), Mg nanoparticles by HPMR method, and $\mathrm{Mg}_{50} \mathrm{Co}_{50}$ bcc alloy) the Mg thinfilm sample is the optimized sample with superior hydrogen absorption kinetics and good thermal conductivity. By SEM observation, the key thickness size of the $\mathrm{Mg}$ thin film is obtained and this makes it possible for the evaluation of thermal physical properties.

2.2. Morphology Observation. Figure 4 compares the observation results from TEM and SEM techniques. The similar information obtained by SEM and TEM methods is the size and shape of the Mg nanoparticles. After hydrogen plasma 


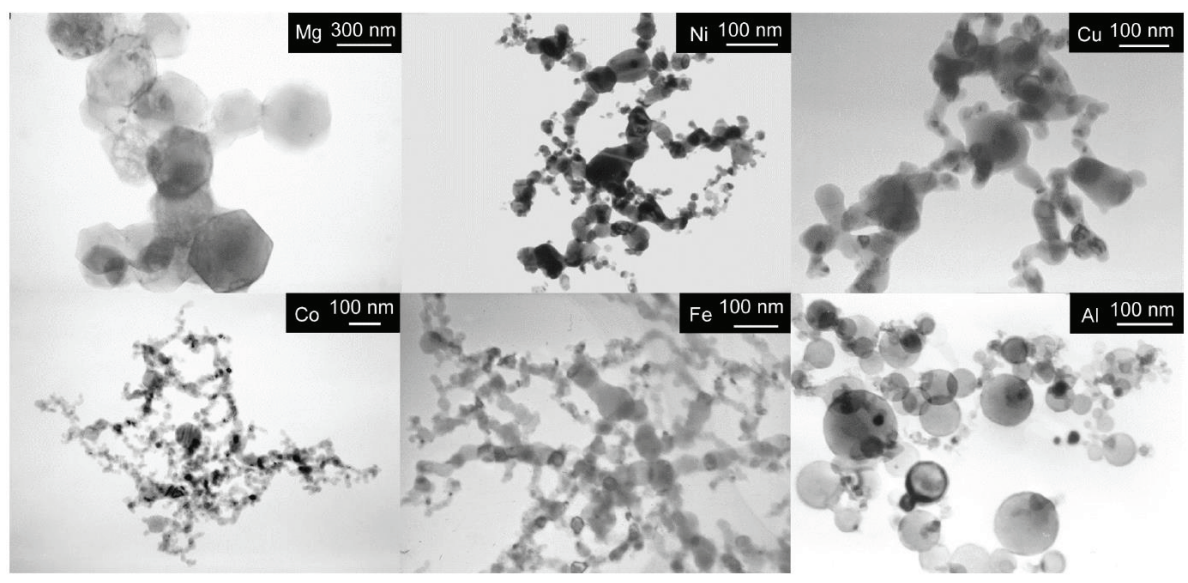

Figure 1: TEM images of different metal nanoparticles synthesized by the hydrogen plasma metal reaction method ( $\mathrm{Mg}, \mathrm{Ni}, \mathrm{Cu}, \mathrm{Co}, \mathrm{Fe}$, and Al) (reproduced with permission from [8]).

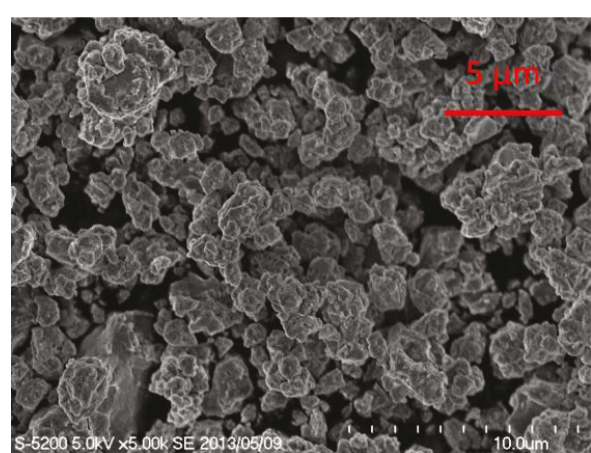

(a)

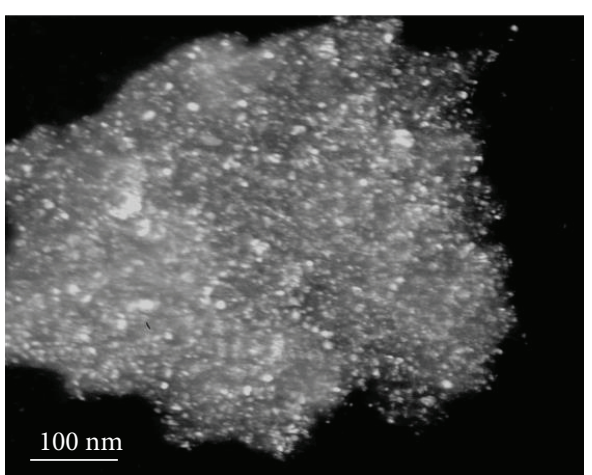

(b)

FIGURE 2: (a) SEM image and (b) dark-field TEM image of the $\mathrm{Mg}_{50} \mathrm{Co}_{50}$ alloy with a body-centered cubic structure synthesized by ball milling for $100 \mathrm{~h}$ (reproduced with permission from [50]).

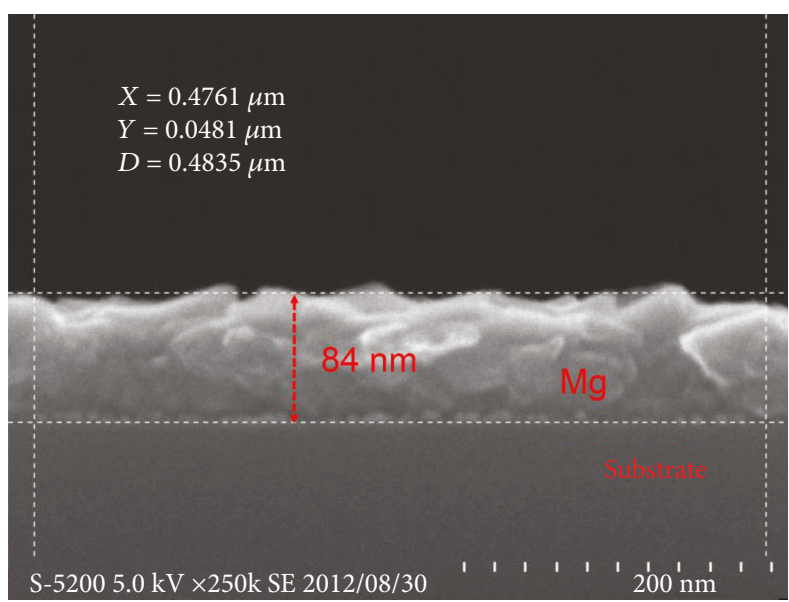

FIgURE 3: SEM image of the cross-sectional observation of the $\mathrm{Mg}$ thin film on a glass substrate (reproduced with permission from [50]).

synthesis, the obtained $\mathrm{Mg}$ nanoparticles have a size from tens of $\mathrm{nm}$ to a few hundred $\mathrm{nm}$ and the average size is around $300-500 \mathrm{~nm}$. Most of the $\mathrm{Mg}$ particles have a hexagonal structure. The main difference lies in the dimensional information. TEM provides a 2-dimensional image, while the SEM may provide a 3-dimensional one.

Figure 5 presents the SEM images of two Mg samples. Figure 5(a) shows commercialized $\mathrm{Mg}$ particles with a mean size of $40-50 \mu \mathrm{m}$. Figure $5(\mathrm{~b})$ shows the $\mathrm{Mg}$ thin film deposited on a glass substrate by a direct current magnetron sputtering technique. The crystallite size of $\mathrm{Mg}$ on the film surface is around $50-100 \mathrm{~nm}$. From the SEM observation in Figure 5(b), the shape of the small crystal domain is a hexagonal structure, which means that the thin-film synthesis is along the c-axis since the basal plane (0001) of a hexagonal close-packed $\mathrm{Mg}$ has the minimum surface energy [54]. Together with the $\mathrm{Mg}$ nanoparticles in Figure 4, we may see that the $\mathrm{Mg}$ samples by different synthesis methods may present quite a different morphology although both have a hexagonal structure. The SEM technique offers the possibility to observe the surface morphology of the samples.

2.3. Phase and Composition Determination. Figure 6 shows the result of the SEM observation and elemental analysis of the $\mathrm{Mg}_{50} \mathrm{Co}_{50}$ sample milled for just $0.5 \mathrm{~h}$. Milling the 


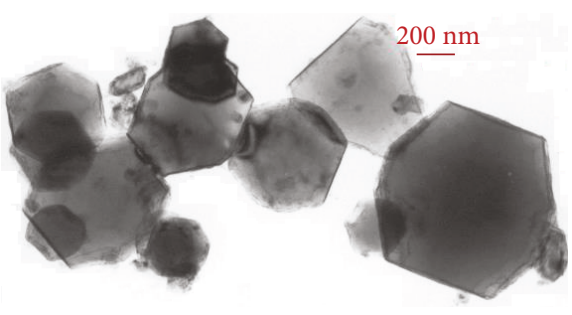

(a)

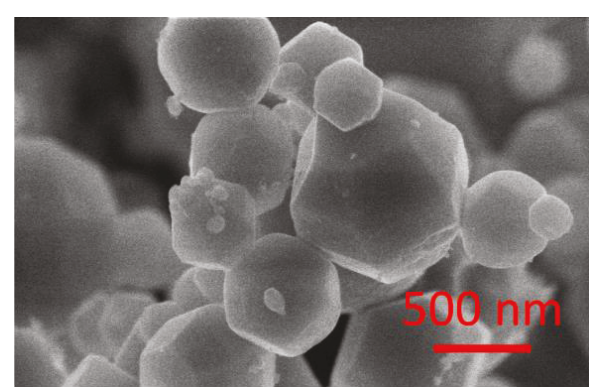

(b)

FIGURE 4: (a) TEM image and (b) SEM image of Mg nanoparticles synthesized by the HPMR method (reproduced with permission from $[50,53])$.

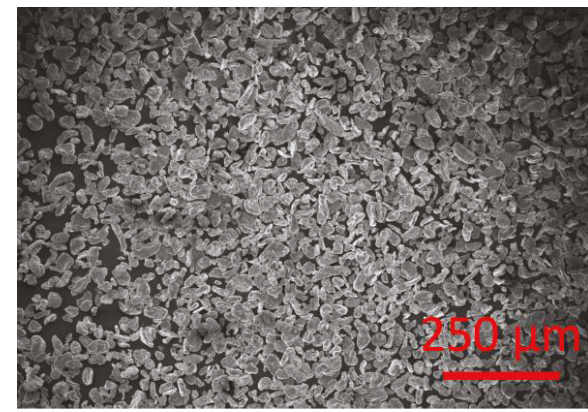

(a)

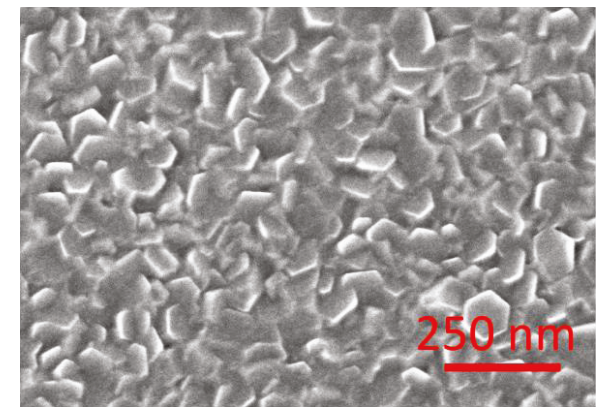

(b)

Figure 5: SEM images of (a) 325 mesh Mg particles from Alfa Aesar and (b) top view of the Mg thin film on a glass substrate (reproduced with permission from [50]).

mixture sample for $100 \mathrm{~h}$ results in the formation of the $\mathrm{Mg}_{50} \mathrm{Co}_{50}$ alloy with a bcc structure. After milling for only $0.5 \mathrm{~h}$, it has mainly two $\mathrm{Mg}$ and Co phases, which can be confirmed from EDS mapping and X-ray diffraction measurements [49]. When we combine the EDS mapping results with the SEM image, we can see that the small white color particles are Co and the large dark ones are Mg. Here it may demonstrate that through the combination of SE-SEM and BSE-SEM observations as well as EDS elemental analysis mapping and X-ray diffraction techniques, a comprehensive understanding of the phase and composition of the samples may be acquired.

Figure 7 presents the bright-field TEM image and electron diffraction of the bcc-structured $\mathrm{Mg}_{50} \mathrm{Co}_{50}$ alloy. In Figure 2, we already discussed that this bcc-structured $\mathrm{Mg}_{50} \mathrm{Co}_{50}$ alloy is uniform in size with a particle size of a few $\mu \mathrm{m}$ and a crystallite size of a few $\mathrm{nm}$. The XRD result shows a set of well-broadened reflection peaks [21, 51] and from the broadening, the crystallite size is calculated to be $1-5 \mathrm{~nm}$. In this size, there is no clear boundary between the nanocrystallite and amorphous state, and it is difficult to determine the local lattice structure based on the broadened reflection peaks. However, the electron diffraction characterization attached on the TEM equipment may provide some key information about the lattice structure of the $\mathrm{Mg}_{50} \mathrm{Co}_{50}$ alloy after milling for $100 \mathrm{~h}$. After we measured the radii of the electron diffraction rings in Figure $7(b)$, it was found that the radii $\left(R_{1}\right.$ to $\left.R_{6}\right)$ of the diffraction rings from the inside to the outside agree well with the rule of (1).

$$
R_{1}^{2}: R_{2}^{2}: R_{3}^{2}: R_{4}^{2}: R_{5}^{2}: R_{6}^{2}=1: 2: 3: 4: 5: 6 \text {. }
$$

This unique accordance indicates that the $\mathrm{Mg}_{50} \mathrm{Co}_{50}$ alloy is well indexed as a bcc structure. Here we may see that sometimes, electron diffraction measurements along with SEM may provide a key local lattice structure of the samples, especially when the samples are at a scale of several $\mathrm{nm}$.

Figure 8 presents TEM images of a typical $\mathrm{MgH}_{2}$ polycrystalline particle in the $\mathrm{MgH}_{2}$ nanocrystallite sample by a homogeneously catalyzed solution synthesis $[20,55,56]$. This particle has a size of $200-300 \mathrm{~nm}$ and some catalyzed $\mathrm{Ti}$ with an amorphous-like phase or a crystalline state is confirmed to be located mainly on the rims of the $\mathrm{MgH}_{2}$ nanocrystals. Figure 8(b) shows one $\mathrm{MgH}_{2}$ domain with a size of about $50 \mathrm{~nm}$. Since the observation of the TEM images is under a high quality vacuum, it is necessary to prove that the observed area is $\mathrm{MgH}_{2}$ and not $\mathrm{Mg}$ due to evacuation or $\mathrm{MgO}$ from oxidization. This key information can be provided from the indexed lattice fringes in Figure 8(c). The three spacings in Figure 8(c) of $0.25,0.25$, and $0.32 \mathrm{~nm}$ are in good agreement with the distances of (01-1), (110), and (101) planes of the $\mathrm{MgH}_{2}$ phase, respectively. This also indicates the electron beam parallel to the (11-1) zone 


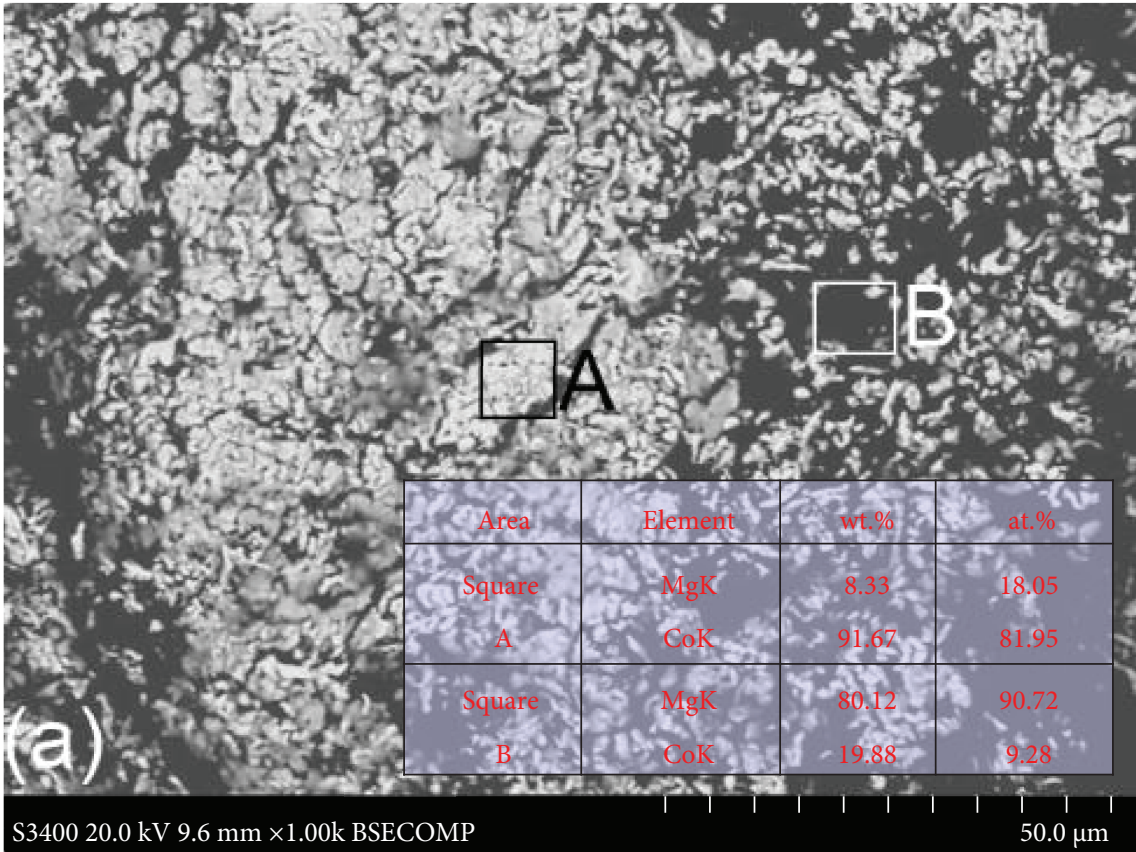

(a)

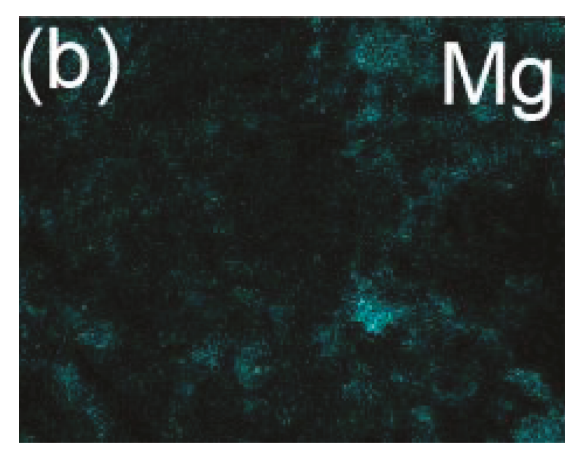

(b)

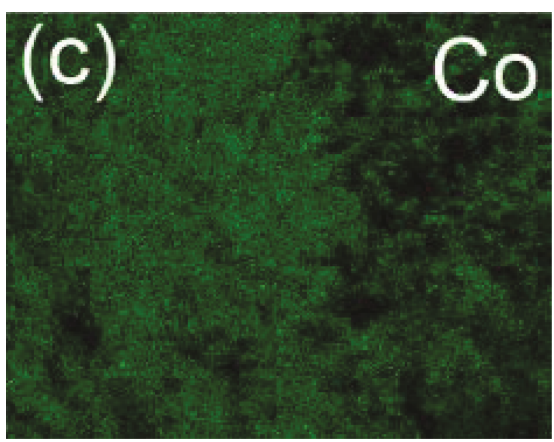

(c)

FIgure 6: (a) BSE-SEM image of the $\mathrm{Mg}_{50} \mathrm{Co}_{50}$ sample milled for $0.5 \mathrm{~h}$ and the EDS mapping of the $\mathrm{Mg}$ element (b) and Co element (c). The inserted table provides the EDS quantitative results of elemental analysis in the selected square areas of A and B in (a) (reproduced with permission from [49]).

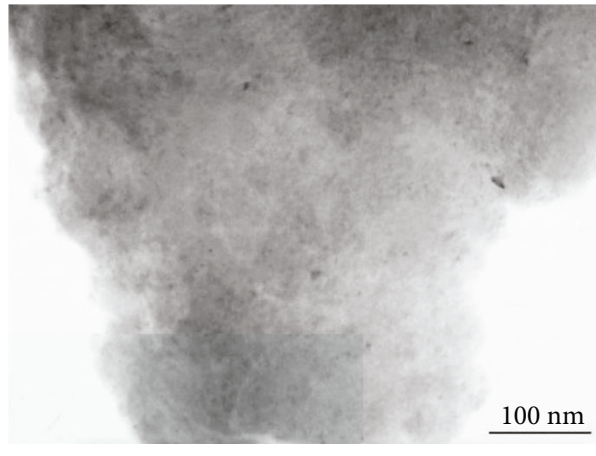

(a)

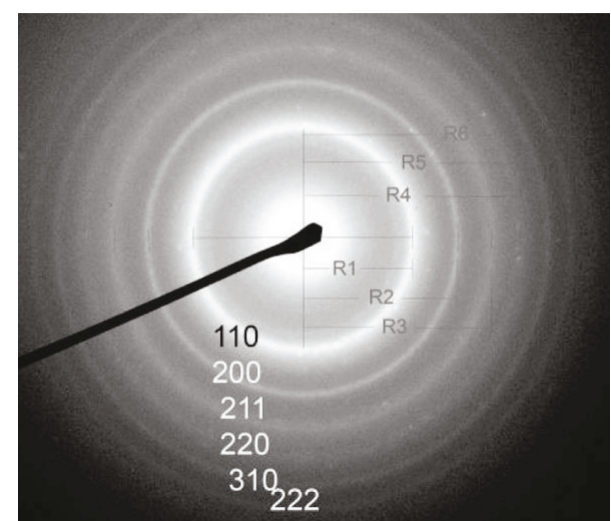

(b)

FIGURE 7: (a) Bright-field TEM image and (b) indexed electron diffraction pattern of the $\mathrm{Mg}_{50} \mathrm{Co}_{50}$ alloy with a bcc structure synthesized by ball milling for $100 \mathrm{~h}$ (reproduced with permission from [51]).

axis. Here we can see that HR-TEM observation and lattice fringe indexation may provide some key information for phase determination in the selected area.

2.4. Understanding the Formation Mechanism. XRD may provide the phase and composition of the samples. SEM may present morphology information of the samples, especially on the surface of the particles. The combination of SEM and XRD may be very helpful to the understanding of the evolution mechanism during the synthesis and formation process. Figures 9 and 10 present the BSE-SEM images and
XRD patterns of the $\mathrm{Mg}_{50} \mathrm{Co}_{50}$ samples milled for various durations from 0.5 to $400 \mathrm{~h}[49,51]$. From the XRD curves, we may clarify the formation mechanism of the phases in the $\mathrm{Mg}_{50} \mathrm{Co}_{50}$ samples milled from 0.5 to $400 \mathrm{~h}$, as in (2) (hcp means hexagonal close packed and fcc means facecentered cubic).

$$
\begin{aligned}
\mathrm{Mg}+\mathrm{Co}-\mathrm{h} c \mathrm{p} & \rightarrow \mathrm{Mg}_{\text {nano }}+\mathrm{Co}_{\text {nano }}-\mathrm{hcp} \\
& \rightarrow \mathrm{Mg}_{\text {nano }}+\mathrm{Co}_{\text {nano }}-\mathrm{hcp}+\mathrm{Co}_{\text {nano }}-\mathrm{fcc} \\
& \rightarrow \mathrm{bcc}+\mathrm{Co}_{\text {nano }}-\mathrm{fcc} \rightarrow \mathrm{bcc} .
\end{aligned}
$$




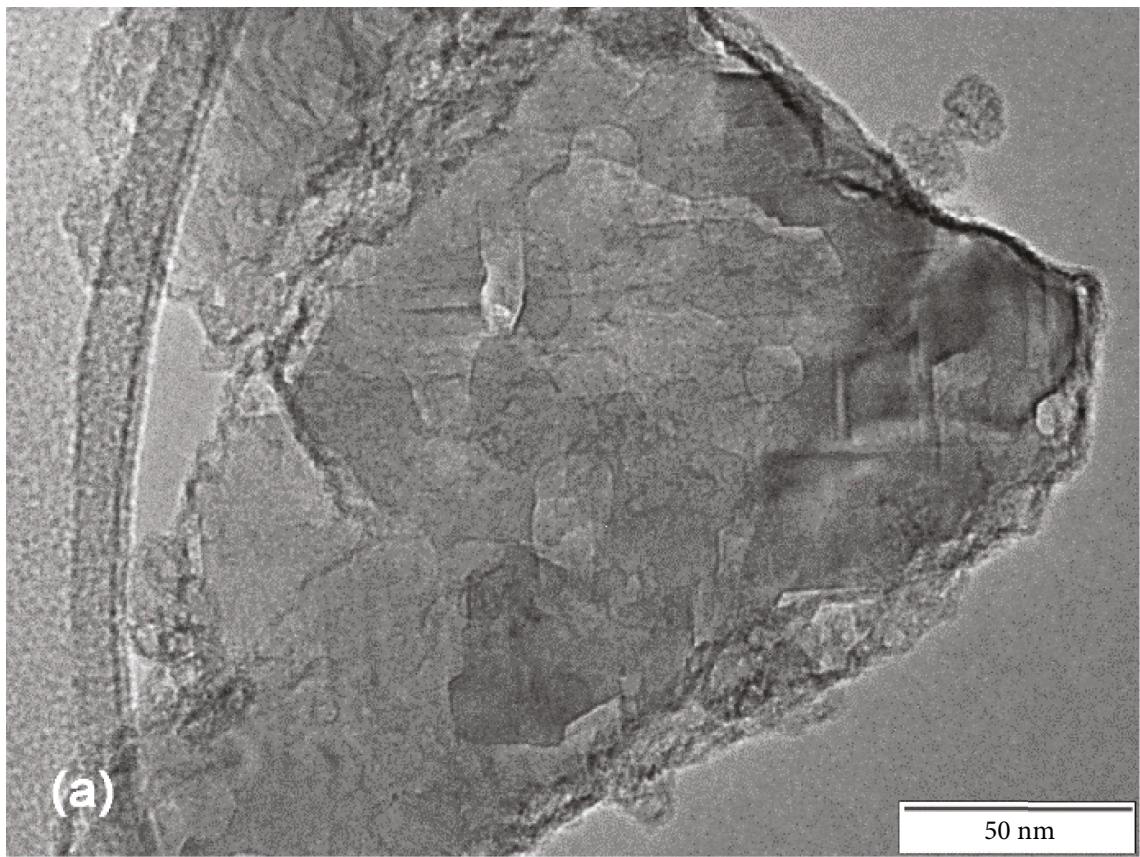

(a)

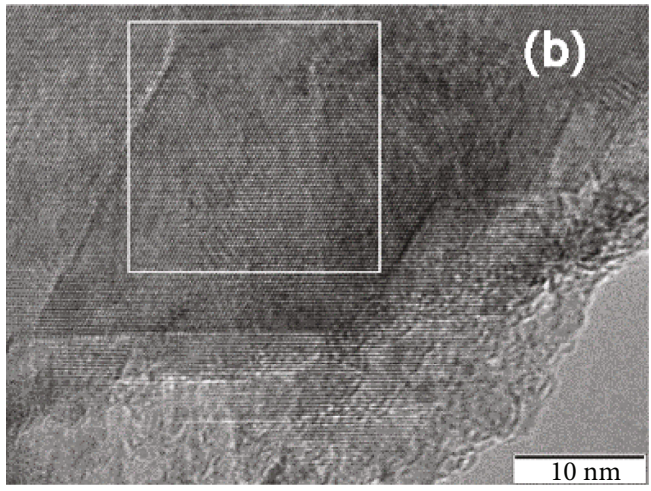

(b)

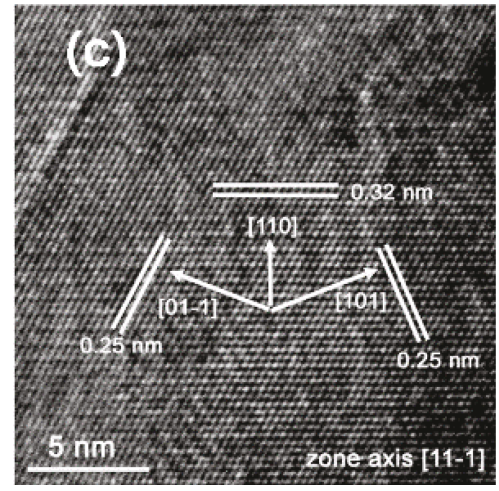

(c)

Figure 8: TEM images of (a) a typical $\mathrm{MgH}_{2}$ particle in the catalyzed $\mathrm{MgH}_{2}$ nanocrystallite sample, (b) a typical $\mathrm{MgH}_{2}$ nanocrystal area, and (c) a lattice spacing and orientation indexed area marked in (b) (reproduced with permission [20]).

With the combination of the SEM in Figure 9 and the $\mathrm{XRD}$ results, the phase and morphology evolution process during the milling of $\mathrm{Mg}_{50} \mathrm{Co}_{50}$ samples from 0.5 to $400 \mathrm{~h}$ can be summarized as follows: firstly, with the beginning of the ball milling, small Co particles are well dispersed on the big Mg particles; secondly, large Mg particles are cracked into small ones and Co particles stick on the surface of $\mathrm{Mg}$ particles; thirdly, after around $25 \mathrm{~h}$ of milling, the Co phase with an fcc structure is formed and Co particles dissolve into the $\mathrm{Mg}$ ones; fourthly, particle sizes continue to decrease and the bcc phase appears after $45 \mathrm{~h}$ of milling; and fifthly, after $100 \mathrm{~h}$, only the bcc phase with a crystallite size of only a few $\mathrm{nm}$ remains and the particles of the $\mathrm{Mg}_{50} \mathrm{Co}_{50}$ samples change from irregular shapes to round ones from further welding during the milling. The combination of SEM observation and XRD phase identification may offer an important solution to the understanding of the formation evolution mechanisms.
2.5. Correlation Study of Properties and Microstructure. It is well known that the physical and chemical properties of samples can be greatly affected by the microstructure of the samples including shape, particle size, size distribution, and surface morphology, which can be well evaluated by TEM and SEM techniques. Figure 11 presents the TEM images of the $\mathrm{Mg}$ nanoparticles before and after hydrogen absorption and desorption processes. Figure 12 demonstrates the first and second cycles of the hydrogen absorption kinetics of $\mathrm{Mg}$ nanoparticles. We have already discussed the microstructure of $\mathrm{Mg}$ nanoparticles as prepared by the HPMR method $[8,50,53]$. In Figure 11(b), we may see that the hydrogenated sample, $\mathrm{MgH}_{2}$ (Mg hydride), has a very light and transparent feature compared to the $\mathrm{Mg}$ nanoparticles. This is due to the fact that Mg nanoparticles in Figure 11(a) are in a metal state, while the $\mathrm{MgH}_{2}$ nanoparticles have a semiconductor feature. This difference makes the two samples show different optical characteristics under an electron 


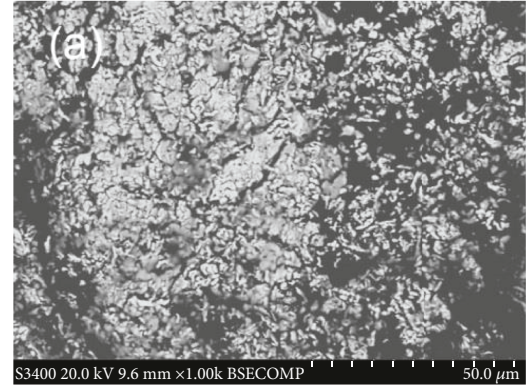

(a)

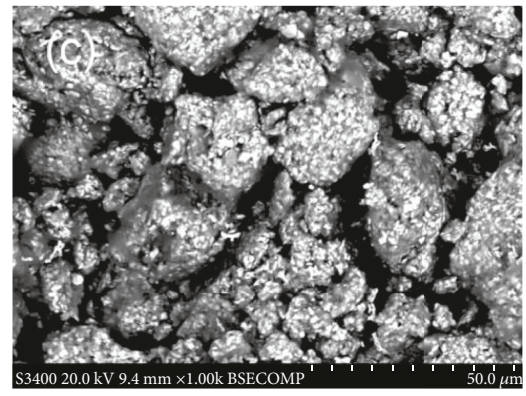

(c)

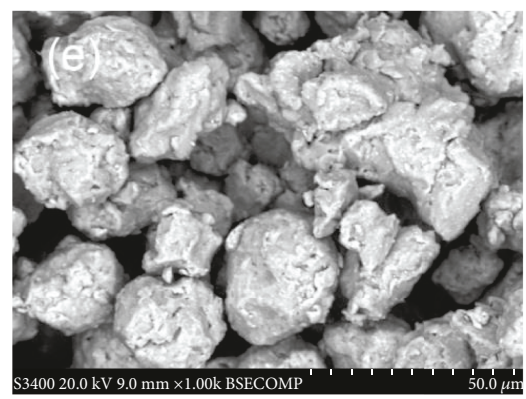

(e)

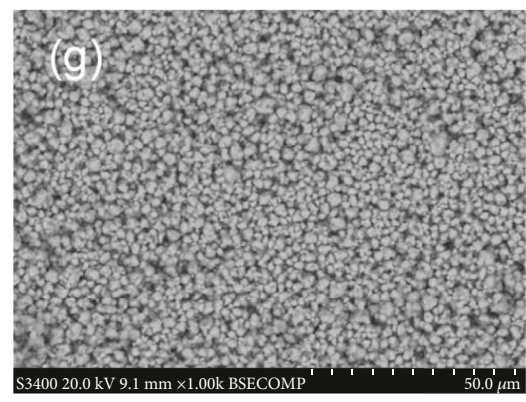

(g)

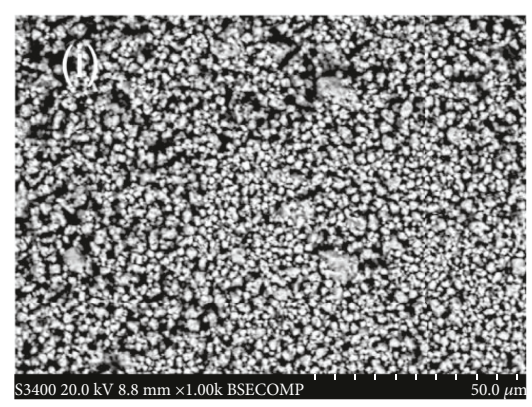

(i)

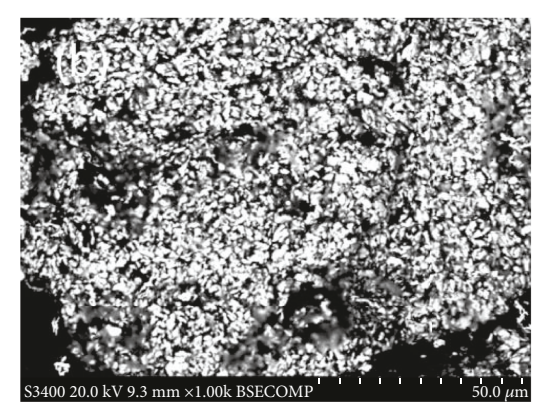

(b)

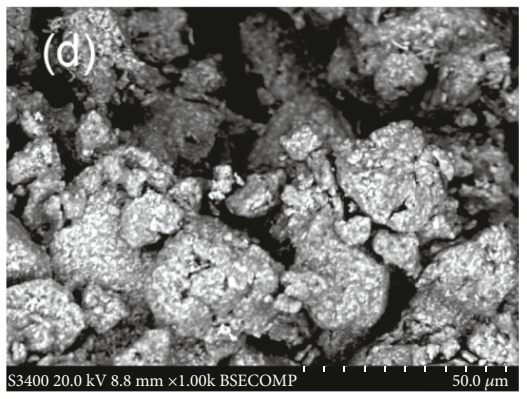

(d)

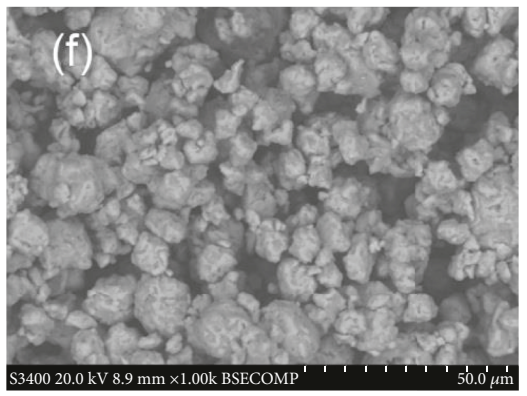

(f)

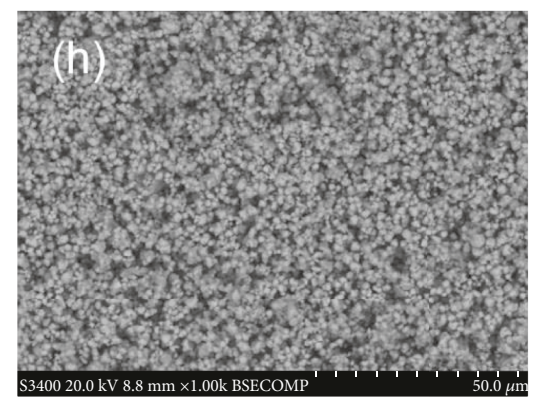

(h)

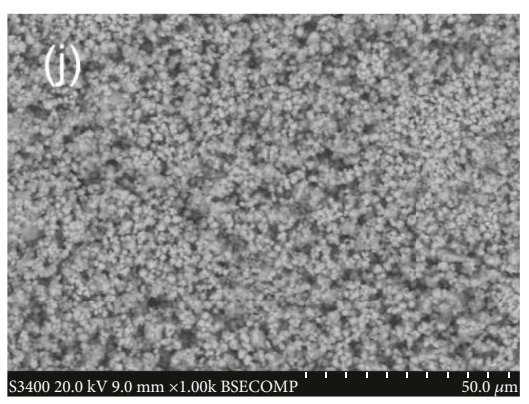

(j)

Figure 9: Continued. 


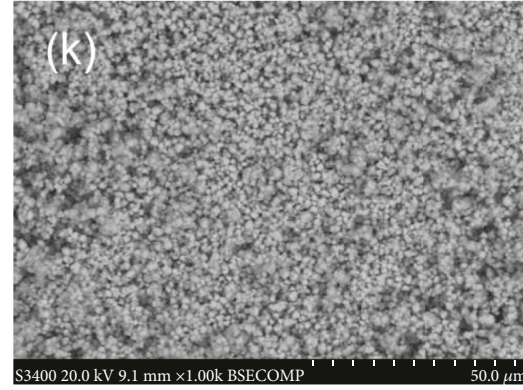

(k)

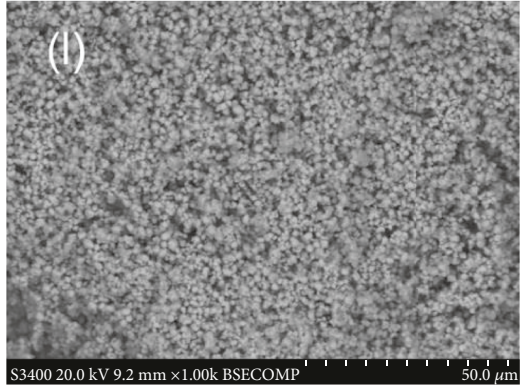

(1)

Figure 9: BSE-SEM images (at a magnification of 1000) of the $\mathrm{Mg}_{50} \mathrm{Co}_{50}$ samples milled at the following durations: (a) $0.5 \mathrm{~h}$, (b) $2 \mathrm{~h}$, (c) $5 \mathrm{~h}$, (d) $10 \mathrm{~h}$, (e) $25 \mathrm{~h}$, (f) $40 \mathrm{~h}$, (g) $50 \mathrm{~h}$, (h) $75 \mathrm{~h}$, (i) $100 \mathrm{~h}$, (j) $200 \mathrm{~h}$, (k) $300 \mathrm{~h}$, and (l) $400 \mathrm{~h}$ (reproduced with permission from [49]).

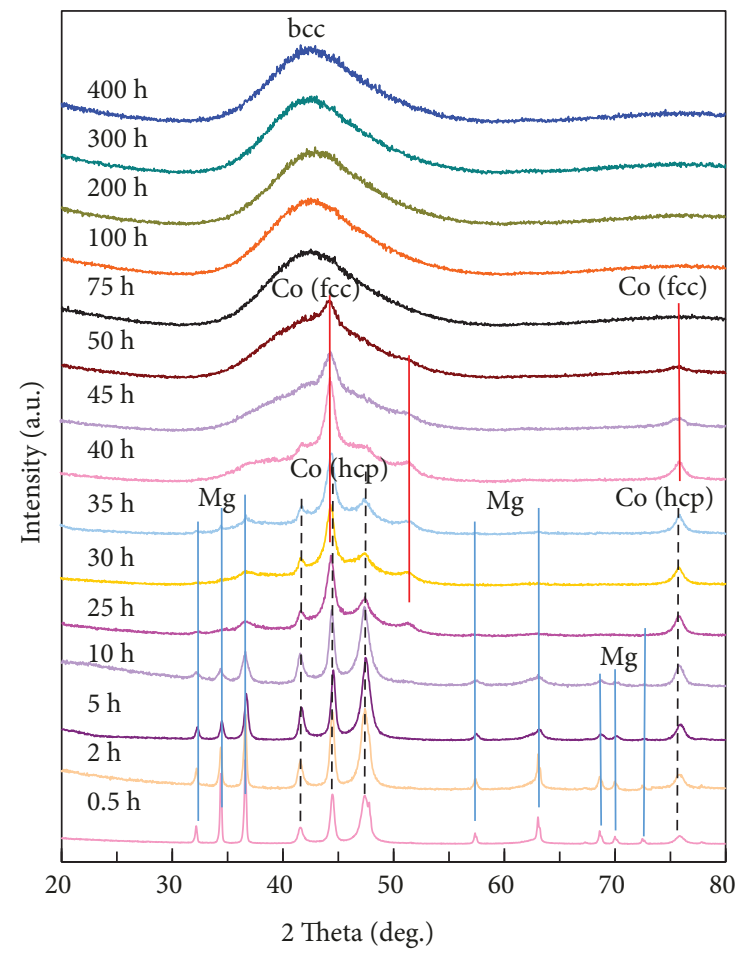

Figure 10: XRD patterns of the $\mathrm{Mg}_{50} \mathrm{Co}_{50}$ samples ball milled for various durations (0.5 to $400 \mathrm{~h}$ ) (reproduced with permission from [49]).

beam. Actually, this phenomenon is applied for the research and development of metal hydride-based switchable mirrors [57-60]. Besides this difference, when we compare the asprepared Mg nanoparticles (Figure 11(a)) with the Mg nanoparticles after hydrogen absorption and desorption cycles (Figure 11(c)), we can see that the sample of Mg nanoparticles after hydrogen storage cycles show broken surfaces and some sponge-like particles. This is because the particle surfaces are cracked due to the entry and exit of hydrogen atoms during the hydrogen absorption and desorption processes. This morphology difference is thought to play an important role in the hydrogen storage properties of the samples.

In Figure 12, we can see from the hydrogen absorption curves that the $\mathrm{Mg}$ nanoparticle sample by the HPMR method at the first cycle absorbs 7.53 wt.\% hydrogen in $65 \mathrm{~min}$, while it absorbs almost the same amount of hydrogen at the second and third cycles only after less than $15 \mathrm{~min}$ absorption. The Mg nanoparticles had not been subjected to the activation procedure before the three absorption cycles discussed in the previous line: this testifies to the superior hydrogen absorption properties of the nanoparticles prepared by the HPMR method. When we combine the TEM observation results and the ones with the hydrogen absorption kinetics together, we may see that the microstructure change on the surface of the Mg nanoparticles significantly influences the hydrogen absorption properties of the samples. This demonstrates that advanced TEM and SEM microscopy techniques may play essential roles in clarifying relationships between the properties and microstructures of the materials.

2.6. In Situ Observation of Hydrogen Reaction Mechanism. In situ scanning techniques are very helpful to understand the hydrogenation and dehydrogenation reactions of $\mathrm{Mg}$-based materials. As a result, direct observations could be obtained to strongly support other experiments such as DSC and TG-MS. Nogita et al. [61] studied the dehydrogenation mechanism of $\mathrm{MgH}_{2}$ in different sizes by in situ TEM. They reported that the hydrogen release mechanism from bulk $\mathrm{MgH}_{2}$ with a particle size of $2 \mu \mathrm{m}$ was based on the growth of the multiple preexisting $\mathrm{Mg}$ grains (crystallite within the $\mathrm{MgH}_{2}$ matrix in Figure 13(a)) present, which was due to the difficulty of fully transforming all of the $\mathrm{Mg}$ during a hydrogenation cycle. On the other hand, in thin samples analogous to nanopowders, dehydrogenation occurs by a "shrinking core" mechanism as shown in Figure 13(b). In the case of $\mathrm{Mg}_{2} \mathrm{NiH}_{4}$, Tran et al. [62] studied the dehydrogenation mechanism of bulk $\mathrm{Mg}_{2} \mathrm{NiH}_{4}$ using in situ TEM. It was found that the dehydrogenation was based on a mechanism of the nucleation and growth of $\mathrm{Mg}_{2} \mathrm{NiH}_{x}(x \sim 0-0.3)$ solid solution grains and was greatly enhanced in the presence of crystal defects occurring as a result of the polymorphic phase transformation as shown in Figure 13(c). Also importantly, with atomic resolution TEM imaging, a high density of stacking faults is identified in the dehydrogenated $\mathrm{Mg}_{2} \mathrm{NiH}_{x}(x \sim 0-0.3)$ lattices. $\mathrm{Zhu}$ et al. [46] adopted the method of hydriding chemical vapor deposition to synthesize a single-crystal $\mathrm{MgH}_{2}$ nanofiber. Then, the phase change of 


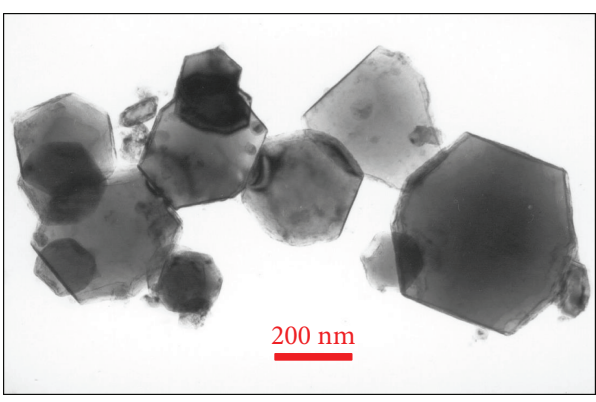

(a)

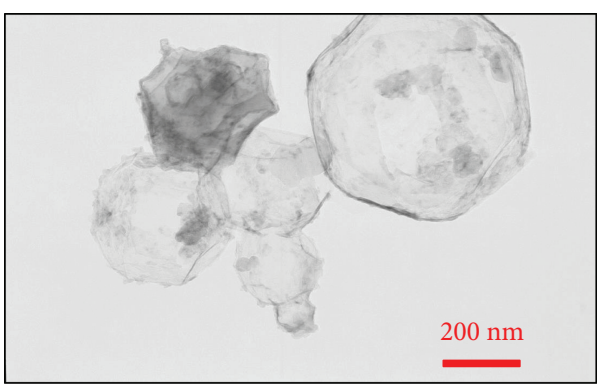

(b)

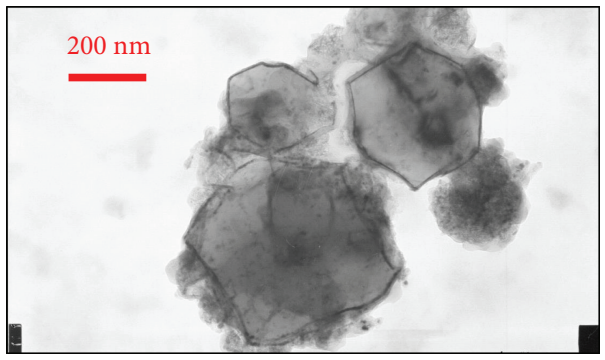

(c)

Figure 11: TEM images of (a) Mg nanoparticles synthesized by a hydrogen plasma metal reaction method, (b) $\mathrm{MgH}_{2}$ nanoparticles after hydrogenation of the Mg sample in (a), and (c) the Mg nanoparticle sample after hydrogen absorption and desorption steps (reproduced with permission [53]).

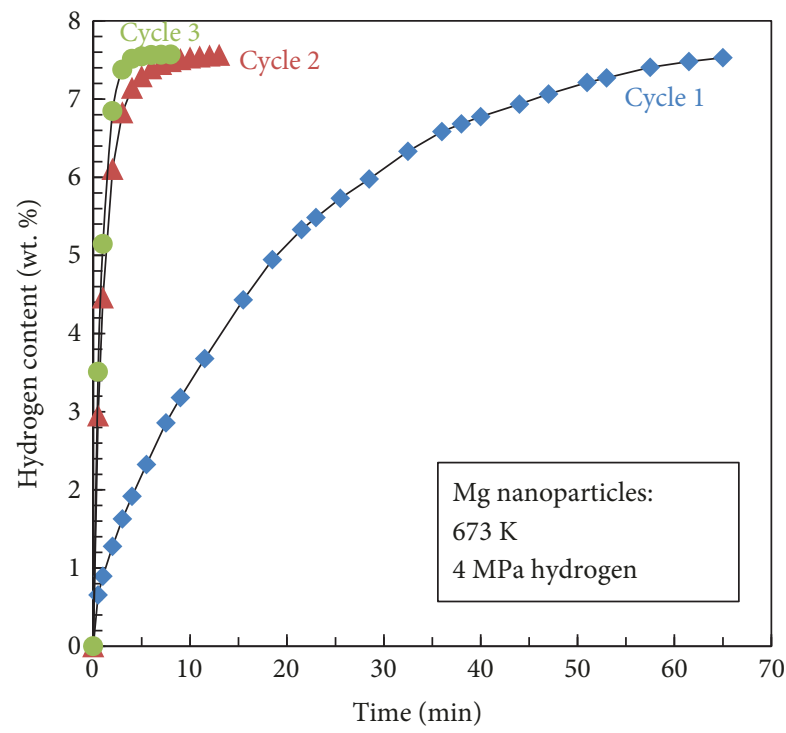

Figure 12: The first three hydrogen absorption curves in $4 \mathrm{MPa}$ hydrogen atmosphere and at $673 \mathrm{~K}$ for $\mathrm{Mg}$ nanoparticles prepared by the HPMR method (reproduced with permission [53]).

the as-obtained $\mathrm{MgH}_{2}$ nanofiber in the desorption process was observed with the in situ TEM. The results indicated that the orientation relationship between $\mathrm{MgH}_{2}$ and $\mathrm{Mg}$ during the phase change was one of the zone axis of $\mathrm{MgH}_{2}$ (110) parallel to the $\mathrm{Mg}$ (0001) zone axis, or one of the plane (110) of $\mathrm{MgH}_{2}$ parallel to the basal plane of $\mathrm{Mg}$ (0001). Similar results were reported by Paik et al. [43].

Besides the pure $\mathrm{MgH}_{2}$ and bulk $\mathrm{Mg}_{2} \mathrm{NiH}_{4}$, the catalysts were also introduced into the $\mathrm{MgH}_{2}$ to investigate the microstructural changes by in situ techniques in the dehydrogenation process. Isobe et al. [42] ball milled the $\mathrm{MgH}_{2}$ with different amounts of $\mathrm{Nb}_{2} \mathrm{O}_{5}$ to study the effects of $\mathrm{Nb}_{2} \mathrm{O}_{5}$ on the desorption of $\mathrm{MgH}_{2}$ by in situ TEM. It was found that the $\mathrm{MgH}_{2}$ doped by $1 \mathrm{~mol} \% \mathrm{Nb}_{2} \mathrm{O}_{5}$ started at $150^{\circ} \mathrm{C}$ and then the nanosized $\mathrm{Mg}$ was formed, while the desorption of $\mathrm{MgH}_{2}$ catalyzed with $10 \mathrm{~mol} \%$ started at the interface between $\mathrm{MgH}_{2}$ and $\mathrm{Nb}_{2} \mathrm{O}_{5}$ with the temperature increasing, which suggested that hydrogen atoms could diffuse from the $\mathrm{MgH}_{2}$ phase to the interface between the $\mathrm{MgH}_{2}$ and $\mathrm{Nb}_{2} \mathrm{O}_{5}$. Similarly, Kim et al. [44] also prepared the $\mathrm{NbF}_{5}$-doped $\mathrm{MgH}_{2}$ by ball milling and then studied the microstructural changes in the desorption process of the as-prepared sample by in situ TEM. Results showed that the amorphous Nb-F thin layer contacted the $\mathrm{MgH}_{2}$ phase at $25^{\circ} \mathrm{C}$, while the amorphous Nb-F layer was transformed to a metallic $\mathrm{Nb}$ crystalline layer after complete desorption at $250^{\circ} \mathrm{C}$. Based on the above analysis, the in situ technique allows researchers to clearly study the samples in real time under special conditions (such as by heating or at a certain atmosphere), which may strongly support other analyses. In a word, the in situ technique is a powerful strategy to grasp more information from the samples than traditional microscopy.

\section{Summary and Prospects}

The utilization of SEM and TEM techniques for characterizing the size, morphology observation, phase and composition determination, and formation and reaction mechanisms in Mg-based hydrogen storage materials fabricated by different nanoprocessing methods are presented in this paper. Although the information obtained by SEM and TEM about the size and shape of Mg-based materials are similar, TEM 


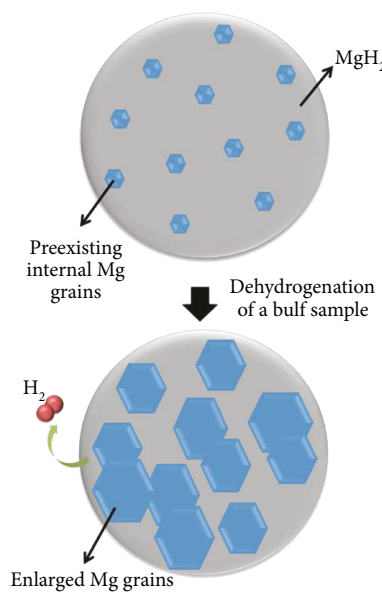

(a)
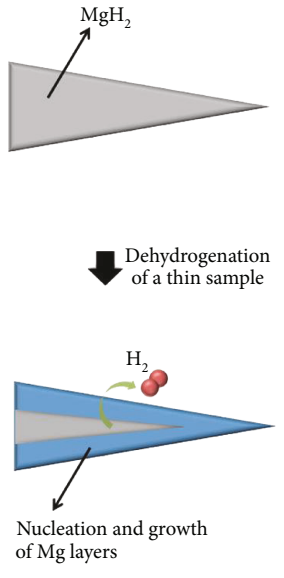

(b)

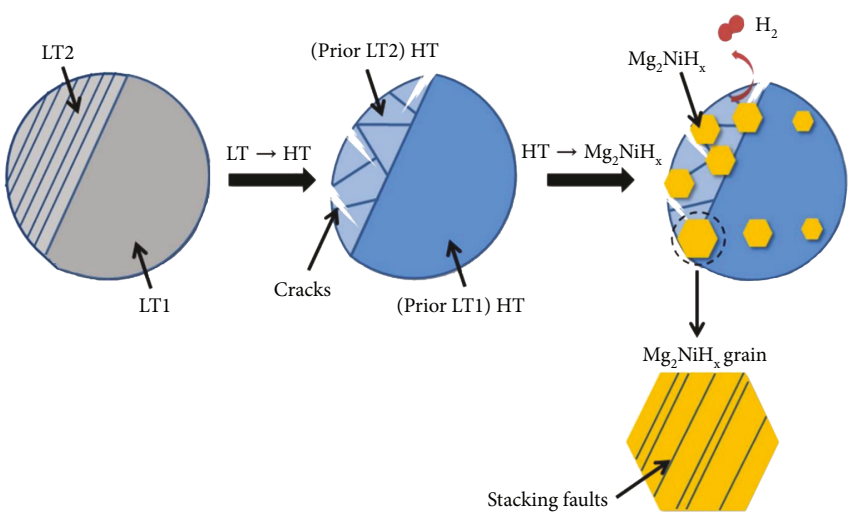

(c)

Figure 13: Schematic of hydrogen release mechanisms from (a) bulk $\mathrm{MgH}_{2}$, (b) thin $\mathrm{MgH}_{2}$, and (c) bulk $\mathrm{Mg}_{2} \mathrm{NiH}_{4}$ samples (reproduced with permission from $[61,62]$ (under the Creative Commons Attribution License/public domain)).

provides a $2 \mathrm{D}$ image of the particles while SEM may obtain a $3 \mathrm{D}$ one. Using the TEM measurement, we could easily obtain the size, size distribution, and average size of various $\mathrm{Mg}$ based samples. The SEM technique also offers the possibility to observe the surface morphology. Additionally, we may well understand the phase, composition, and structure and formation mechanism of $\mathrm{Mg}$-based hydrogen storage materials by the combination of different techniques. However, conventional electron microscopies have challenges compared with in situ scanning techniques when studying the hydrogen reaction mechanism. A special sample holder which may transfer samples from the glove box to the TEM/SEM equipment presents great advantages when it comes to observing sensitive samples. In situ electron microscopy can be allowed to study some changes of the Mg-based materials in real time under special conditions and in turn directly verify the hydrogen reaction mechanism. As modern science moves from studies of structure and ground states to dynamics and functionalities, electron microscopy will clearly experience a revolutionary growth in capabilities in the next decade, from ultrasmall to ultrafast and to multidimensions, which could result in transformative advances in many fields of science and engineering [63].

\section{Conflicts of Interest}

The authors declare no conflict of interest.

\section{Acknowledgments}

Huaiyu Shao acknowledges the Macau Science and Technology Development Fund (FDCT) for funding (project no. 118/ 2016/A3). This work was also partially supported by a StartUp Research Fund from the Universidade de Macau (SRG2016-00088-FST). Huaijun Lin thanks the financial support from the National Natural Science Foundation of China (no. 51601090).

\section{References}

[1] J. Yang, A. Sudik, C. Wolverton, and D. J. Siegel, "High capacity hydrogen storage materials: attributes for automotive applications and techniques for materials discovery," Chemical Society Reviews, vol. 39, no. 2, pp. 656675, 2010.

[2] M. Zhu, Y. Lu, L. Ouyang, and H. Wang, "Thermodynamic tuning of Mg-based hydrogen storage alloys: a review," Materials, vol. 6, no. 10, pp. 4654-4674, 2013.

[3] H. Zhang, X. Zheng, X. Tian, Y. Liu, and X. Li, "New approaches for rare earth-magnesium based hydrogen storage alloys," Progress in Natural Science: Materials International, vol. 27, no. 1, pp. 50-57, 2017.

[4] T. Sadhasivam, H. T. Kim, S. Jung, S. H. Roh, J. H. Park, and H. Y. Jung, "Dimensional effects of nanostructured $\mathrm{Mg}$ / $\mathrm{MgH}_{2}$ for hydrogen storage applications: a review," Renewable \& Sustainable Energy Reviews, vol. 72, pp. 523-534, 2017.

[5] B. Sakintuna, F. Lamari-Darkrim, and M. Hirscher, "Metal hydride materials for solid hydrogen storage: a review," International Journal of Hydrogen Energy, vol. 32, no. 9, pp. 1121-1140, 2007.

[6] J.-C. Crivello, B. Dam, R. V. Denys et al., "Review of magnesium hydride-based materials: development and optimisation," Applied Physics A, vol. 122, no. 2, p. 97, 2016.

[7] H. Shao, "Heat modeling and material development of Mg-based nanomaterials combined with solid oxide fuel cell for stationary energy storage," Energies, vol. 10, no. 11, p. $1767,2017$.

[8] H. Shao, G. Xin, J. Zheng, X. Li, and E. Akiba, "Nanotechnology in Mg-based materials for hydrogen storage," Nano Energy, vol. 1, no. 4, pp. 590-601, 2012.

[9] H. Shao, L. He, H. Lin, and H.-W. Li, "Progress and trends in magnesium-based materials for energy-storage research: a review," Energy Technology, vol. 6, no. 3, pp. 445-458, 2018.

[10] H. Wang, H. J. Lin, W. T. Cai, L. Z. Ouyang, and M. Zhu, "Tuning kinetics and thermodynamics of hydrogen storage in light metal element based systems - a review of recent progress," Journal of Alloys and Compounds, vol. 658, pp. 280-300, 2016. 
[11] C. J. Webb, “A review of catalyst-enhanced magnesium hydride as a hydrogen storage material," Journal of Physics and Chemistry of Solids, vol. 84, pp. 96-106, 2015.

[12] H. Shao, Y. T. Wang, and X. G. Li, "Synthesis and properties of nanostructured $\mathrm{Mg}_{2} \mathrm{Ni}$-based compounds," Materials Science Forum, vol. 475-479, no. 3, pp. 2445-2448, 2005.

[13] L. Xie, H. Y. Shao, Y. T. Wang, Y. Li, and X. G. Li, "Synthesis and hydrogen storing properties of nanostructured ternary Mg-Ni-Co compounds," International Journal of Hydrogen Energy, vol. 32, no. 12, pp. 1949-1953, 2007.

[14] H. Shao, H. Xu, Y. Wang, and X. Li, "Synthesis and hydrogen storage behavior of $\mathrm{Mg}-\mathrm{Co}-\mathrm{H}$ system at nanometer scale," Journal of Solid State Chemistry, vol. 177, no. 10, pp. 36263632, 2004.

[15] H. Shao, T. Liu, and X. Li, "Preparation of the $\mathrm{Mg}_{2} \mathrm{Ni}$ compound from ultrafine particles and its hydrogen storage properties," Nanotechnology, vol. 14, no. 3, pp. L1-L3, 2003.

[16] H. Shao, T. Liu, Y. Wang, H. Xu, and X. Li, "Preparation of Mg-based hydrogen storage materials from metal nanoparticles," Journal of Alloys and Compounds, vol. 465, no. 1-2, pp. 527-533, 2008.

[17] H. Shao, T. Liu, X. Li, and L. Zhang, "Preparation of $\mathrm{Mg}_{2} \mathrm{Ni}$ intermetallic compound from nanoparticles," Scripta Materialia, vol. 49, no. 6, pp. 595-599, 2003.

[18] H. Shao, K. Asano, H. Enoki, and E. Akiba, "Preparation and hydrogen storage properties of nanostructured $\mathrm{Mg}-\mathrm{Ni} \mathrm{BCC}$ alloys," Journal of Alloys and Compounds, vol. 477, no. 1-2, pp. 301-306, 2009.

[19] H. Shao, Y. Wang, H. Xu, and X. Li, "Preparation and hydrogen storage properties of nanostructured $\mathrm{Mg}_{2} \mathrm{Cu}$ alloy," Journal of Solid State Chemistry, vol. 178, no. 7, pp. 2211-2217, 2005.

[20] H. Shao, M. Felderhoff, F. Schuth, and C. Weidenthaler, "Nanostructured Ti-catalyzed $\mathrm{MgH}_{2}$ for hydrogen storage," Nanotechnology, vol. 22, no. 23, article 235401, 2011.

[21] J. Matsuda, H. Shao, Y. Nakamura, and E. Akiba, "The nanostructure and hydrogenation reaction of $\mathrm{Mg}_{50} \mathrm{Co}_{50} \mathrm{BCC}$ alloy prepared by ball-milling," Nanotechnology, vol. 20, no. 20, article 204015, 2009.

[22] H. Shao, K. Asano, H. Enoki, and E. Akiba, "Fabrication and hydrogen storage property study of nanostructured Mg-Ni-B ternary alloys," Journal of Alloys and Compounds, vol. 479, no. 1-2, pp. 409-413, 2009.

[23] H. Shao and X. Li, "Effect of nanostructure and partial substitution on gas absorption and electrochemical properties in $\mathrm{Mg}_{2} \mathrm{Ni}$-based alloys," Journal of Alloys and Compounds, vol. 667, pp. 191-197, 2016.

[24] M. Huang, L. Ouyang, J. Liu, H. Wang, H. Shao, and M. Zhu, "Enhanced hydrogen generation by hydrolysis of $\mathrm{Mg}$ doped with flower-like $\mathrm{MoS}_{2}$ for fuel cell applications," Journal of Power Sources, vol. 365, pp. 273-281, 2017.

[25] H. Shao, C. Chen, T. Liu, and X. Li, "Phase, microstructure and hydrogen storage properties of Mg-Ni materials synthesized from metal nanoparticles," Nanotechnology, vol. 25, no. 13, article 135704, 2014.

[26] T. Liu, H. Shen, Y. Liu et al., "Scaled-up synthesis of nanostructured Mg-based compounds and their hydrogen storage properties," Journal of Power Sources, vol. 227, pp. 86-93, 2013.

[27] J. Zhang, Y. Zhu, H. Lin et al., "Metal hydride nanoparticles with ultrahigh structural stability and hydrogen storage activity derived from microencapsulated nanoconfinement," Advanced Materials, vol. 29, no. 24, 2017.

[28] E. Callini, L. Pasquini, E. Piscopiello, A. Montone, M. V. Antisari, and E. Bonetti, "Hydrogen sorption in $\mathrm{Pd}$ decorated Mg-MgO core-shell nanoparticles," Applied Physics Letters, vol. 94, no. 22, article 221905, 2009.

[29] K. J. Jeon, H. R. Moon, A. M. Ruminski et al., “Air-stable magnesium nanocomposites provide rapid and high-capacity hydrogen storage without using heavy-metal catalysts," Nature Materials, vol. 10, no. 4, pp. 286-290, 2011.

[30] A. Anastasopol, T. V. Pfeiffer, A. Schmidt-Ott, F. M. Mulder, and S. W. H. Eijt, "Fractal disperse hydrogen sorption kinetics in spark discharge generated $\mathrm{Mg} / \mathrm{NbOx}$ and Mg/Pd nanocomposites," Applied Physics Letters, vol. 99, no. 19, article 194103, 2011.

[31] J. Ditto, D. Krinsley, and K. Langworthy, "Localized grounding, excavation, and dissection using in-situ probe techniques for focused ion beam and scanning electron microscopy: experiments with rock varnish," Scanning, vol. 34, no. 5, 283 pages, 2012.

[32] B. J. Crawford and R. D. Burke, "TEM and SEM methods," Methods in Cell Biology, vol. 74, pp. 411-441, 2004.

[33] L. Reimer, "Electron diffraction methods in TEM, STEM and SEM," Scanning, vol. 2, no. 1, 19 pages, 1979.

[34] B. Bokhonov, E. Ivanov, and V. Boldyrev, "A study of the electron-beam-induced decomposition of magnesium hydride single crystals," Materials Letters, vol. 5, no. 5-6, pp. 218-221, 1987.

[35] O. Friedrichs, J. C. Sánchez-López, C. López-Cartes et al., "Chemical and microstructural study of the oxygen passivation behaviour of nanocrystalline $\mathrm{Mg}$ and $\mathrm{MgH}_{2}$," Applied Surface Science, vol. 252, no. 6, pp. 2334-2345, 2006.

[36] M. Porcu, A. K. Petford-Long, and J. M. Sykes, "TEM studies of $\mathrm{Nb}_{2} \mathrm{O}_{5}$ catalyst in ball-milled $\mathrm{MgH}_{2}$ for hydrogen storage," Journal of Alloys and Compounds, vol. 453, no. 1-2, pp. 341346, 2008.

[37] A. Zaluska, L. Zaluski, and J. O. Ström-Olsen, "Nanocrystalline magnesium for hydrogen storage," Journal of Alloys and Compounds, vol. 288, no. 1-2, pp. 217-225, 1999.

[38] M. Zhu, H. Wang, L. Ouyang, and M. Zeng, "Composite structure and hydrogen storage properties in Mg-base alloys," International Journal of Hydrogen Energy, vol. 31, no. 2, pp. 251-257, 2006.

[39] N. Hanada, E. Hirotoshi, T. Ichikawa, E. Akiba, and H. Fujii, "SEM and TEM characterization of magnesium hydride catalyzed with Ni nano-particle or $\mathrm{Nb}_{2} \mathrm{O}_{5}$," Journal of Alloys and Compounds, vol. 450, no. 1-2, pp. 395-399, 2008.

[40] G. Xia, Y. Tan, X. Chen et al., "Monodisperse magnesium hydride nanoparticles uniformly self-assembled on graphene," Advanced Materials, vol. 27, no. 39, pp. 5981-5988, 2015.

[41] M. Danaie and D. Mitlin, "TEM analysis of the microstructure in $\mathrm{TiF}_{3}$-catalyzed and pure $\mathrm{MgH}_{2}$ during the hydrogen storage cycling," Acta Materialia, vol. 60, no. 19, pp. 6441-6456, 2012.

[42] S. Isobe, A. Ono, H. Yao, Y. Wang, N. Hashimoto, and S. Ohnuki, "Study on reaction mechanism of dehydrogenation of magnesium hydride by in situ transmission electron microscopy," Applied Physics Letters, vol. 96, no. 22, article 223109, 2010.

[43] B. Paik, I. P. Jones, A. Walton, V. Mann, D. Book, and I. R. Harris, " $\mathrm{MgH}_{2} \rightarrow \mathrm{Mg}$ phase transformation driven by a highenergy electron beam: an in situ transmission electron 
microscopy study," Philosophical Magazine Letters, vol. 90, no. 1, pp. 1-7, 2010.

[44] J. W. Kim, J.-P. Ahn, D. H. Kim et al., "In situ transmission electron microscopy study on microstructural changes in $\mathrm{NbF}_{5}$-doped $\mathrm{MgH}_{2}$ during dehydrogenation," Scripta Materialia, vol. 62, no. 9, pp. 701-704, 2010.

[45] S. D. Beattie, U. Setthanan, and G. S. McGrady, "Thermal desorption of hydrogen from magnesium hydride $\left(\mathrm{MgH}_{2}\right)$ : an in situ microscopy study by environmental SEM and TEM," International Journal of Hydrogen Energy, vol. 36, no. 10, pp. 6014-6021, 2011.

[46] C. Zhu, N. Sakaguchi, S. Hosokai, S. Watanabe, and T. Akiyama, "In situ transmission electron microscopy observation of the decomposition of $\mathrm{MgH}_{2}$ nanofiber," International Journal of Hydrogen Energy, vol. 36, no. 5, pp. 3600-3605, 2011.

[47] S. B. Rice, C. Chan, S. C. Brown et al., "Particle size distributions by transmission electron microscopy: an interlaboratory comparison case study," Metrologia, vol. 50, no. 6, pp. 663678, 2013.

[48] S. Ohno and M. Uda, "Generation rate of ultrafine metal particles in "hydrogen plasma-metal" reaction," Journal of the Japan Institute of Metals, vol. 48, no. 6, pp. 640-646, 1984.

[49] H. Shao, J. Matsuda, H.-W. Li et al., "Phase and morphology evolution study of ball milled Mg-Co hydrogen storage alloys," International Journal of Hydrogen Energy, vol. 38, no. 17, pp. 7070-7076, 2013.

[50] H. Shao, W. Ma, M. Kohno et al., "Hydrogen storage and thermal conductivity properties of $\mathrm{Mg}$-based materials with different structures," International Journal of Hydrogen Energy, vol. 39, no. 18, pp. 9893-9898, 2014.

[51] H. Shao, K. Asano, H. Enoki, and E. Akiba, "Fabrication, hydrogen storage properties and mechanistic study of nanostructured $\mathrm{Mg}_{50} \mathrm{Co}_{50}$ body-centered cubic alloy," Scripta Materialia, vol. 60, no. 9, pp. 818-821, 2009.

[52] H. Kim, J. Nakamura, H. Shao et al., "Local structural evolution of mechanically alloyed $\mathrm{Mg}_{50} \mathrm{Co}_{50}$ using atomic pair distribution function analysis," Journal of Physical Chemistry C, vol. 115, no. 15, pp. 7723-7728, 2011.

[53] H. Shao, Y. Wang, H. Xu, and X. Li, "Hydrogen storage properties of magnesium ultrafine particles prepared by hydrogen plasma-metal reaction," Materials Science and Engineering: B, vol. 110, no. 2, pp. 221-226, 2004.

[54] M. Norek, W. J. Stepniowski, M. Polanski, D. Zasada, Z. Bojar, and J. Bystrzycki, "A comparative study on the hydrogen absorption of thin films at room temperature deposited on non-porous glass substrate and nano-porous anodic aluminum oxide (AAO) template," International Journal of Hydrogen Energy, vol. 36, no. 18, pp. 11777-11784, 2011.

[55] B. Bogdanović, A. Ritter, and B. Spliethoff, "Active $\mathrm{Mgh}_{2}-\mathrm{Mg}$ systems for reversible chemical energy storage," Angewandte Chemie International Edition in English, vol. 29, no. 3, pp. 223-234, 1990.

[56] B. Bogdanović, S.-t. Liao, M. Schwickardi, P. Sikorsky, and B. Spliethoff, "Catalytic synthesis of magnesium hydride under mild conditions," Angewandte Chemie International Edition in English, vol. 19, no. 10, pp. 818-819, 1980.

[57] S. J. van der Molen, M. S. Welling, and R. Griessen, "Correlated electromigration of $\mathrm{H}$ in the switchable mirror $\mathrm{YH}_{3-\delta}$," Physical Review Letters, vol. 85, no. 18, pp. 3882-3885, 2000.
[58] A. T. M. van Gogh, E. S. Kooij, and R. Griessen, "Isotope effects in switchable metal-hydride mirrors," Physical Review Letters, vol. 83, no. 22, pp. 4614-4617, 1999.

[59] A. Remhof, S. J. van der Molen, A. Antosik, A. Dobrowolska, N. J. Koeman, and R. Griessen, "Switchable mirrors for visualization and control of hydrogen diffusion in transition metals," Physical Review B, vol. 66, no. 2, 2002.

[60] J. N. Huiberts, R. Griessen, J. H. Rector et al., "Yttrium and lanthanum hydride films with switchable optical properties," Nature, vol. 380, no. 6571, pp. 231-234, 1996.

[61] K. Nogita, X. Q. Tran, T. Yamamoto et al., "Evidence of the hydrogen release mechanism in bulk $\mathrm{MgH}_{2}$," Scientific Reports, vol. 5, no. 1, p. 8450, 2015.

[62] X. Q. Tran, S. D. McDonald, Q. Gu et al., "In-situ investigation of the hydrogen release mechanism in bulk $\mathrm{Mg}_{2} \mathrm{NiH}_{4}$," Journal of Power Sources, vol. 341, pp. 130-138, 2017.

[63] Y. Zhu and H. Durr, "The future of electron microscopy," Physics Today, vol. 68, no. 4, pp. 32-38, 2015. 

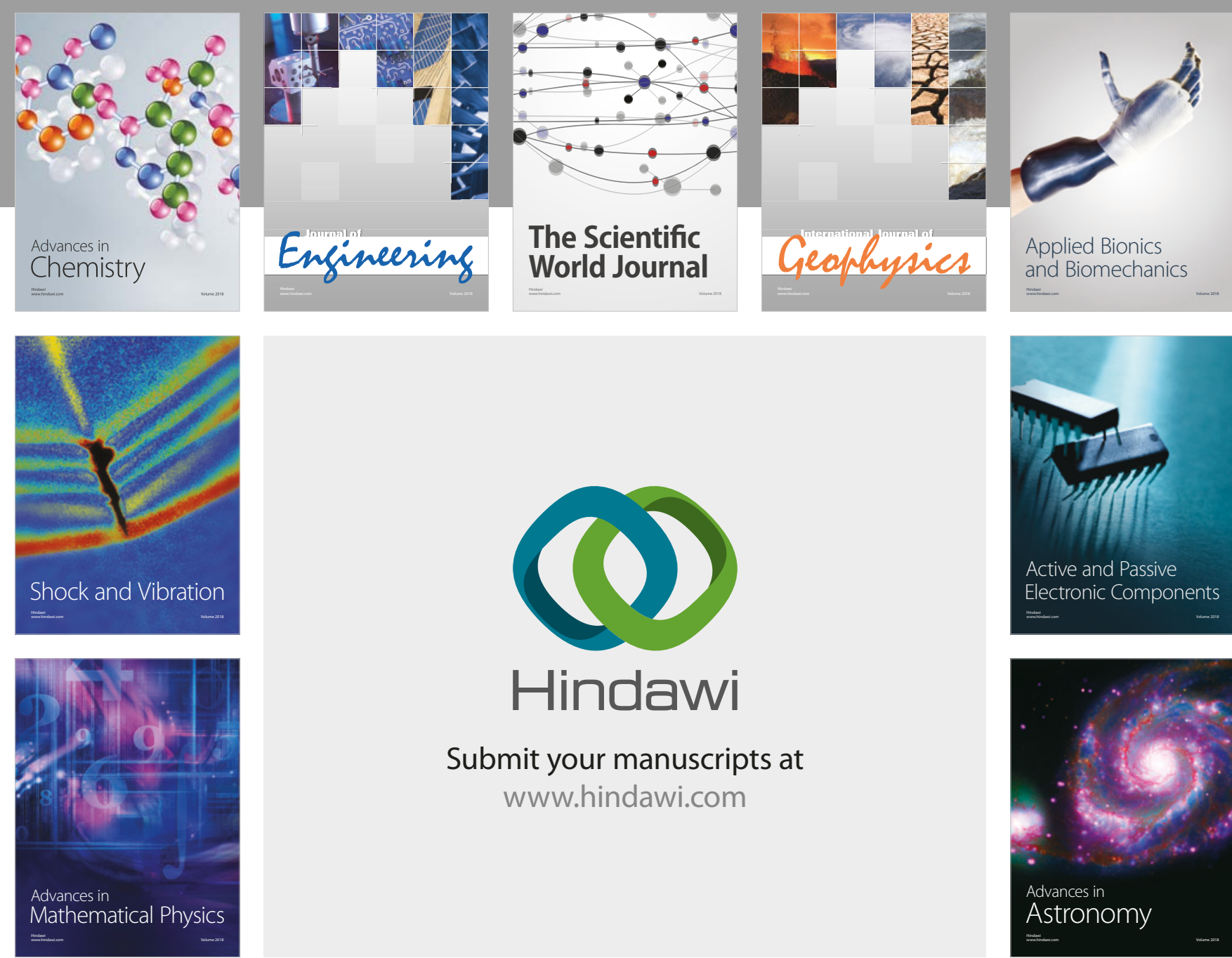

Submit your manuscripts at

www.hindawi.com

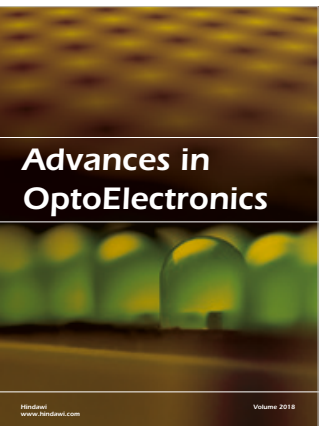

\section{Rotcting Machinery}
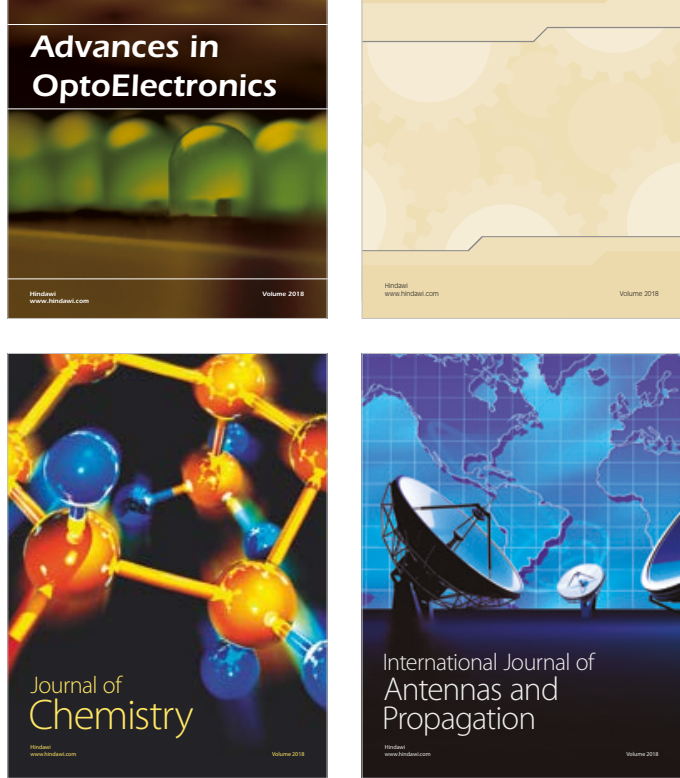

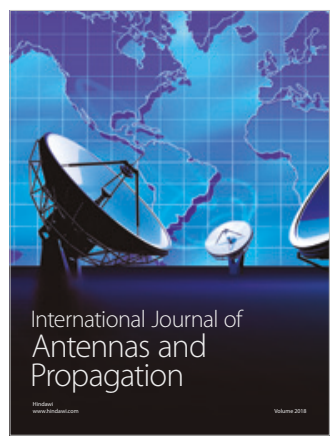

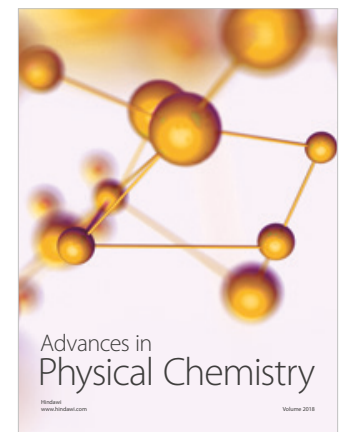

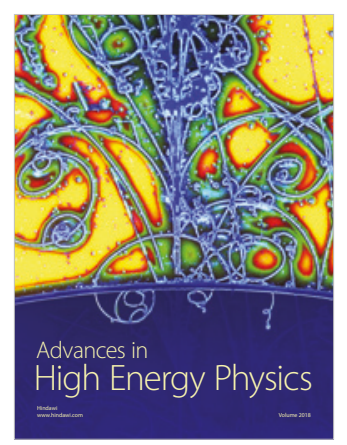

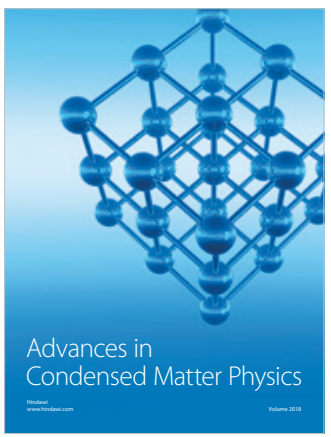

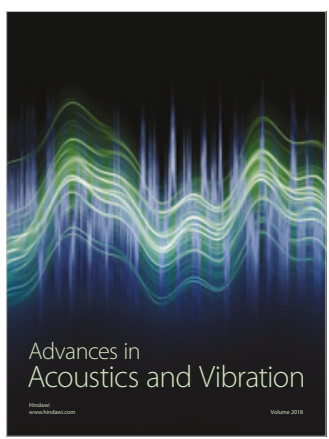

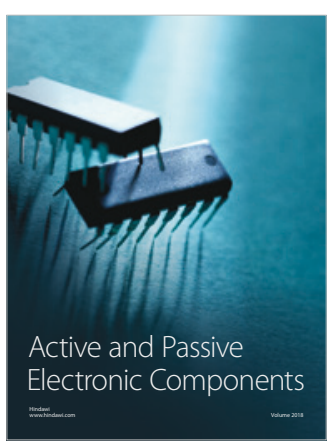
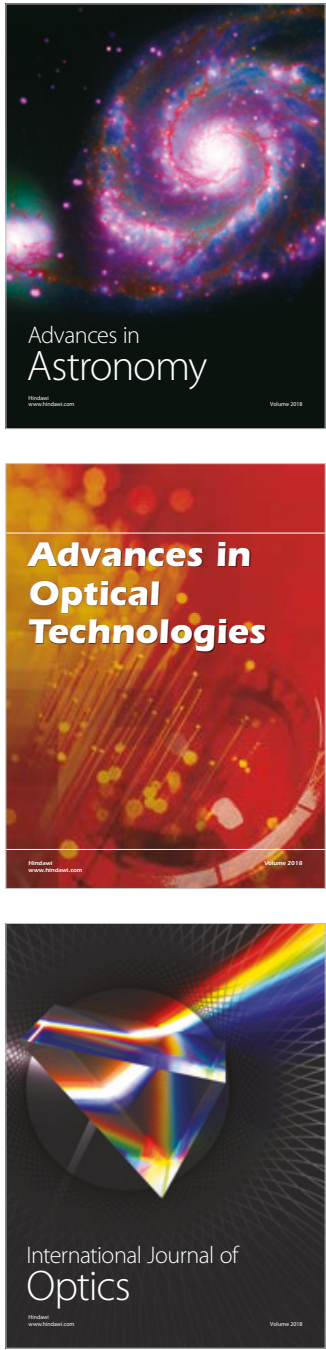